\title{
EDUCAÇÃO NA PANDEMIA DO NOVO CORONAVÍRUS: MÍDIAS E DESIGUALDADE
}

Kelly Maia Cordeiro ${ }^{\mathrm{i}}$

Renato Pontes Costa ${ }^{\text {ii }}$

\begin{abstract}
Resumo: As medidas de distanciamento social impostas pela pandemia do novo coronavírus fizeram com que estudantes em todos os níveis de ensino ficassem sem aulas presenciais em todo o Brasil e no mundo. Tais circunstâncias fortaleceram a discussão sobre mídias na educação e sobre a desigualdade existente no país. Com o objetivo de contribuir com o debate, este artigo apresenta e discute o uso de mídias educativas; resgata o momento histórico do país com o uso do rádio na educação; e reflete sobre o crescimento da desigualdade social. Concluise que as fragilidades na área educacional perpassam pela desigualdade estrutural do país, pela necessidade de democratização do acesso às mídias e sobre o letramento midiático na formação dos sujeitos.
\end{abstract}

Palavras-chave: Covid-19; Desigualdade; Educação; Mídias.

\section{EDUCATION IN THE PANDEMIC OF THE NEW CORONAVIRUS: MEDIA AND INEQUALITY}

\begin{abstract}
The measures of social distance imposed by the pandemic of the new coronavirus meant that students at all levels of education were left without face-to-face classes throughout Brazil and in the world. Such circumstances strengthened the discussion about media in education and about the existing inequality in the country. In order to contribute to the debate, this article presents and discusses the use of educational media; rescues the country's historic moment with the use of radio in education; and reflects on the growth of social inequality. It is concluded that the weaknesses in the educational area run through the country's structural inequality, the need to democratize access to the media and the media literacy in the training of subjects.
\end{abstract}

Keywords: Covid-19; Inequality; Education; Media.

\section{Introdução}

Nesse momento de pandemia do novo coronavírus (Covid-19), o Brasil e o mundo passam por dilemas complexos de serem resolvidos. O "estar bem" envolve muito mais que uma combinação das letras na ortografia correta dessa expressão. A saúde é o principal bem que precisa ser preservado nesse momento e, transversal a esta, há outras dimensões que possuem importância vital para o bem-estar dos seres humanos, como a economia, a política, a ética, a cultura, a educação, entre outras. Tudo isso junto corrobora no sentido do "estar bem", ou do "viver bem" iii, como qualidade de vida plena para toda a humanidade. 
Em meio à pandemia que se instaurou no mundo em 2020, o Brasil atravessa um momento de descompasso entre ações e discursos do governo federal de forma desalinhada com os governos estaduais, o que gera na população muito mais impasses que certezas. Na crise que se instalou, é possível assistir nas plataformas de notícias: o sofrimento da população; o apelo dos médicos em um sistema de saúde em colapso; as dúvidas quanto à estabilidade financeira de diversos setores - trabalhadores formais/informais, pequenos agricultores, microempresários; o aumento do desemprego e da geração de renda; as dificuldades de estudantes e professores em todos os níveis quanto a continuidade da educação.

$\mathrm{Na}$ educação, instaurou-se um dilema quanto à possibilidade de uso de mídias para tentar o menor prejuízo ao cumprimento do ano letivo. Sendo assim, o uso das mídias fomenta uma enorme discussão tanto na academia, quanto na sociedade civil sobre o que fazer, como fazer, se é possível fazer algo que possa minimizar os efeitos desse momento para os sistemas de ensino. Mas o que seria o melhor possível na educação, durante esse período? O que circula no atual debate sobre essa questão?

Este texto pretende discutir o que se tornou um debate na academia e na sociedade civil. A educação a distância, ensino on-line, aula remota/ensino remoto são conceitos existentes e a ideia deste artigo é retomá-los de modo a enriquecer o debate sem negligenciar o potencial do uso das mídias na educação. No bojo dessa discussão, não se pode, contudo, deixar de lado a reflexão sobre a questão da desigualdade tão presente no Brasil, que atravessa e influencia diretamente essa temática.

\section{Educação e mídias no período da pandemia do novo coronavírus: o que sabemos}

Para iniciar essa discussão, foi construído um cronograma relativo ao novo coronavírus que segue dois caminhos e se completam entre si: algumas informações sobre os avanços de casos no mundo, a partir da descoberta do vírus na China; e na área educacional com as principais ações implementadas no Brasil. 
Imagem 1 - Cronograma da epidemia e de algumas ações educacionais ${ }^{\text {iv }}$

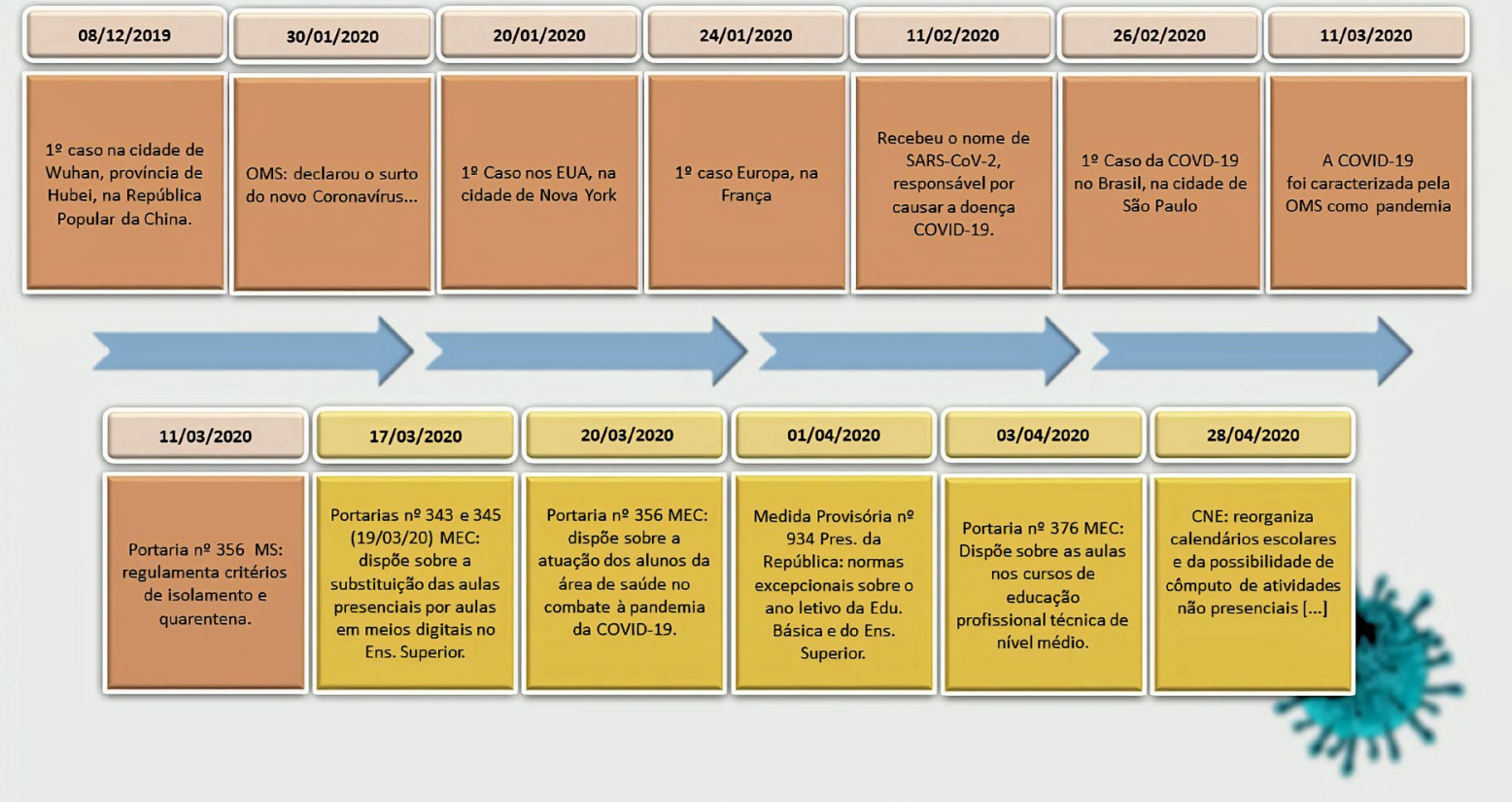

Fonte: Elaborado pelos autores.

Acompanhando a linha do tempo dos principais acontecimentos sobre os progressos do novo coronavírus, percebemos seu rápido avanço até ser diagnosticado no Brasil; o curto período para formular propostas educacionais, levando em consideração a realidade brasileira; e o tempo para aprender com as experiências de enfrentamento em outros países, antes de estabelecer as medidas protetivas.

No cronograma podemos inferir que no mesmo dia em que a Organização Mundial da Saúde (OMS) reconheceu a Covid-19 como pandemia, o Ministério da Saúde (MS) publicou a portaria $n^{0} 356$, de 11 de março de 2020 , com medidas de enfrentamento em decorrência do novo coronavírus. Do mesmo modo, estados e municípios se organizaram, cada qual de acordo com a sua realidade local.

A pandemia tomou conta de praticamente todo o planeta e, sem uma vacina, o único meio mais viável de conter a disseminação do vírus, é o distanciamento social. No Rio de Janeiro e em muitas cidades, o afastamento das escolas começou a partir do dia 16 de março. Entre as estratégias de resguardo à Covid-19, foram incluídas medidas, como: lavar as mãos e evitar aglomerações. Essa demanda reflete em uma nova configuração de ser, de estar nos modos de vida e de aprendizado de toda a população.

Como sinalizado no cronograma, a primeira semana na quarentena foi de ações para se reorganizar a educação. O Ministério da Educação (MEC) começa a divulgar medidas para o ensino superior, autoriza as aulas em meios digitais (BRASIL, 2020b; 2020c), para a educação 
básica em $1^{\circ}$ de abril, com a medida provisória $n^{\circ}$ 934, (BRASIL, 2020e) que em 27 de maio foi prorrogada até agosto de 2020. No final de abril, o Conselho Nacional de Educação (CNE) ${ }^{\mathrm{v}}$ publica um parecer com algumas diretrizes de orientação ao trabalho educacional no período da pandemia para o cumprimento de carga horária (BRASIL, 2020g). As medidas organizacionais tomadas pelos municípios são avaliadas pelo Conselho Municipal de Educação.

Considerando a dimensão territorial do Brasil, não podemos inferir que a organização dos municípios quanto à educação tenha ocorrido de modo linear. Mas, enquanto educadores, percebemos um sonido sobre as mídias. Educação a distância (EaD), educação on-line (EOL), aula/educação remota, plataforma digital, aplicativos educativos... O que usar? Como usar? Ressaltamos que não é objeto deste artigo fazer uma avaliação sobre essas diferentes mídias. Todas têm suas potencialidades, limites e problemáticas.

Entre as formas citadas, a $\mathrm{EaD}$ é a única que tem uma longa história no Brasil. Inicialmente com material impresso, rádio e televisão, posteriormente com acréscimo da possibilidade dos usos de computador, tablet e celular por meio da internet. É constituída como modalidade da educação básica e regida por diferentes medidas de lei - artigo 80 da Lei de Diretrizes e Bases da Educação (LDB, n 9.394/96); decreto $n^{\circ}$ 9.057, de 25 de maio de 2017, que regulamenta o artigo 80 da LDB/96; portaria $\mathrm{n}^{\mathrm{o}} 2.117$, de 6 de dezembro de 2019, que dispõe sobre a oferta de carga horária em cursos de graduação; entre outras. O que representa uma significância quando se refere à educação a distância, uma trajetória consolidada, principalmente para os espaços mais distantes e com dificuldade de acesso.

A EaD tem metodologia e avaliação diferenciadas do contexto presencial. É muito usada na educação superior e na pós-graduação. Para ensino fundamental no contexto da educação em tempos da pandemia, não está sendo recomendada pelo CNE (BRASIL, 2020g). Os estudantes não têm consolidado a prática de estudo a distância, estão em processo de autonomia do aprendizado, uma parcela significativa de estudantes não tem acesso à internet, entre outras questões.

Mesmo havendo certa similaridade entre a $\mathrm{EaD}$ e a educação on-line (EOL), estas são distintas de ensino. Segundo Silva (2012), as principais diferenças estão no formato didático e na mediação da aprendizagem. $\mathrm{Na} \mathrm{EaD}$ o polo emissão e recepção são fixos. Na plataforma do curso são inseridas as atividades predefinidas e organizadas para que os cursistas acessem sem interação direta entre participantes, tratando-se de um modelo didático fixo.

A EOL inicia com uma construção didática predefinida, do individual para o processo coletivo. "O docente é um proponente da formação. Juntamente com os cursistas que promovem 
a cocriação da comunicação e do conhecimento. " (p. 97). Nesse ponto, a proposta de EOL tem mais robustez que a EaD pois o cursista realiza pontos de interação com os participantes, aprende com o material de estudo e com o professor de forma não linear, pela hipertextualidade do contexto virtual de comunicação síncrona e assíncrona. Tem ocorrência em situações formativas de diferentes áreas do conhecimento, por meio da mediação tecnológica em rede. A ilustração a seguir condensa com objetividade princípios para a aula on-line.

\section{Imagem 2 - Princípios da EOL}

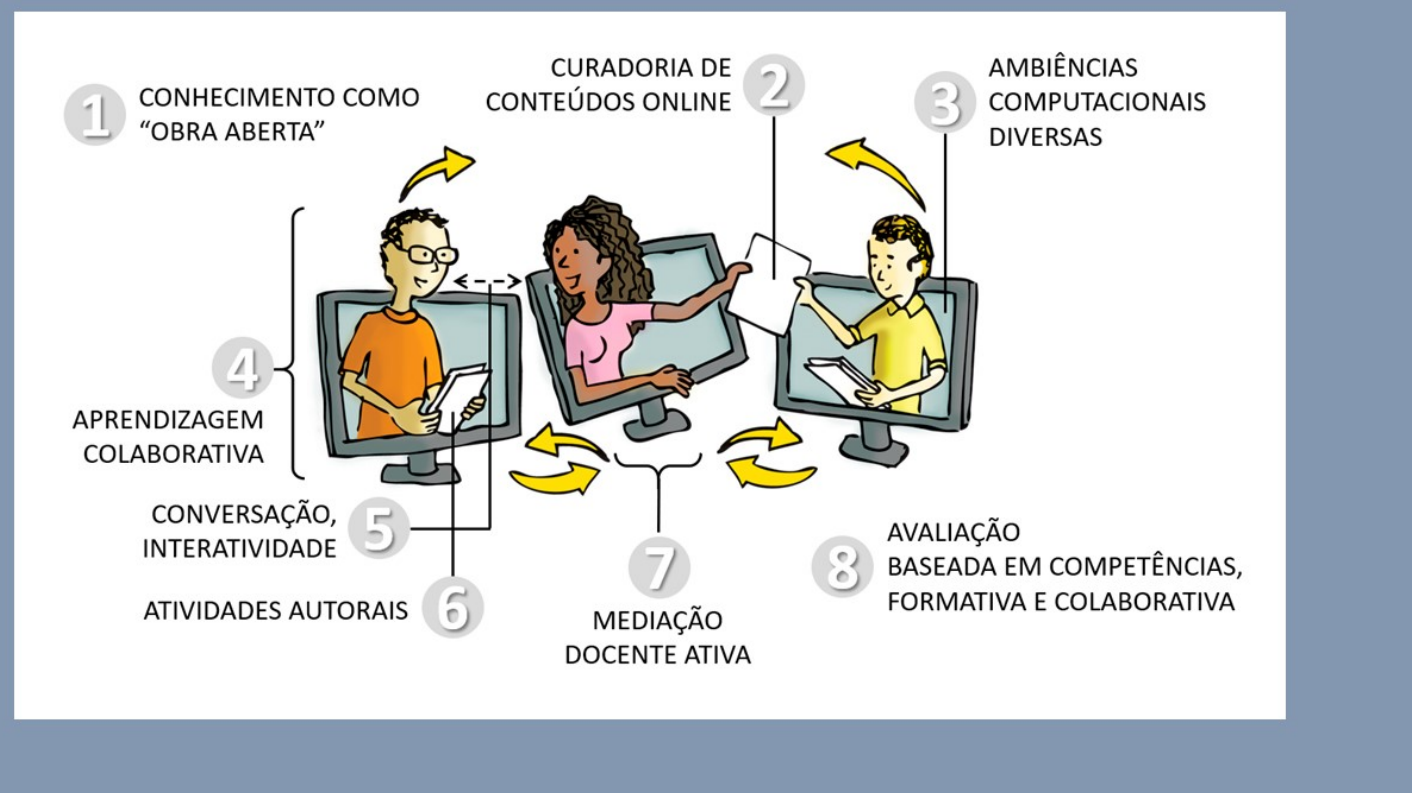

Fonte: Pimentel e Carvalho (2020, on-line).

Durante a pandemia, aula remota/ensino remoto tem sido usada pelas redes de educação privada e pública com estudantes do fundamental II, em curso pré-vestibular, entre outros. Está associada ao momento entre o professor e os estudantes, na ação intencional da ambiência online de aula (Item 3 da ilustração 1). Pode ocorrer em plataformas como Zoom, Google Classroom ou Google Meet, entre outras. Tem como característica o sistema de acesso de transmissão em tempo real; de qualquer espaço; por meio do computador, celular ou tablet; com possibilidade de imagem do professor e alunos na tela, som, compartilhamento de telas, sistema de gravação e outros recursos.

$\mathrm{O}$ contexto da $\mathrm{EaD}$ e da $\mathrm{EOL}$ apresentados evidenciam que não significa transpor do mesmo modo a didática usada nas aulas do presencial para modo virtual. A aula remota implicará para o professor, o uso de didática dinâmica e personalizada. Para o estudante, demanda maior concentração e postura, como por exemplo, ligar/desligar o microfone para 
falar. É importante frisar que ocorreu autorização para substituição de aula presencial por aula em meios digitais e as devidas prorrogações, pelo do Ministério da Educação.

A investigação de Weiser, Blau e Eshet-Alkalai (2018) ${ }^{\text {vi }}$ corrobora com o que foi apresentado sobre estratégias de aprendizagens diferenciadas no EOL. Os autores trazem algumas pistas sobre a interação dos estudantes em educação síncrona, quando realizada no ambiente de aula remota pelo Zoom e com modelagem de estratégias didáticas diferenciadas para esse ambiente. Dos resultados destacamos que: a) os estudantes se mantiveram mais passivos quando o professor era discursivo; b) maior significância nas estratégias que buscavam a participação dos estudantes e aquelas de forma colaborativa entre os estudantes; c) o nível de conhecimento foi gradativo ascendente e percebido pela participação durante as aulas; d) a interação dos estudantes mudava de acordo com o nível de participação que era empregada pelo professor, quanto mais interrogações, mais retorno os estudantes davam; e) com o tempo, as interações (professor-aluno e aluno-aluno) ficaram mais espontâneas e dinâmicas sem a necessidade de tanta intervenção do professor.

A pandemia trouxe a necessidade de reorganizar o ensino e ocorreu a inserção do uso de mídias nas aulas. Uma questão que merece atenção, principalmente no setor público, devido à dificuldade de todos os estudantes ao acesso à internet. E como forma de minimizar as diferenças educacionais, práticas híbridas foram indicadas pelo CNE (BRASIL, 2020g), em um documento com informações e reflexões quanto ao emprego de atividades educativas nesse momento. Considera, como consta também na medida provisória $n^{\circ} 934$ do MEC, que não será possível o cumprimento dos dias letivos de 2020, mas mantém a obrigatoriedade da carga horária como define a LDB/96.

As diretrizes do CNE (BRASIL, 2020g) podem indicar caminhos substanciais aos municípios, pois o documento discorre sobre cada segmento - da educação básica ao ensino superior - com propostas educacionais para o período de afastamento, reconhecendo que:

[...] as atividades pedagógicas não presenciais podem acontecer por meios digitais (videoaulas, conteúdos organizados em plataformas virtuais de ensino e aprendizagem, redes sociais, correio eletrônico, $b \log s$, entre outros); por meio de programas de televisão ou rádio; pela adoção de material didático impresso com orientações pedagógicas distribuído aos alunos e seus pais ou responsáveis; e pela orientação de leituras, projetos, pesquisas, atividades e exercícios indicados nos materiais didáticos. (p. 8, grifo nosso).

Para corroborar com nossa análise, as “atividades pedagógica não presenciais” parecem sinalizar para: abertura para outros modos e formas de estudo nesse período; um caminho possível para as comunidades fora dos centros urbanos, de difícil acesso; afirmação da 
responsabilidade de gestores com a educação para além dos usos da internet; e uma perspectiva de minimizar os danos das desigualdades expressas no Brasil.

A TV e o rádio na educação não são projetos novos no Brasil, retomar o que aprendemos em outros tempos, tem sido o caminho de alguns estados e cidades como propostas além da internet. A Secretaria da Educação e do Esporte do estado do Paraná disponibilizou a transmissão das aulas on-line e por TV aberta para os estudantes de 217 municípios do estado. Seguiram essa mesma linha os estados do Rio de Janeiro - por meio da TV da Assembleia Legislativa (ALERJ) e TV Band - e o estado do Maranhão - com a TV Assembleia e Rádio Timbira. No município de São José da Laje-AL, além da internet está sendo utilizado no período da pandemia o projeto "Rádio Escola" para estudantes em área de acesso com internet deficitária.

A história da educação no Brasil é marcada por muitas experiências de uso do rádio como experiências educativas. É interessante relembrar esse passado que demarcou lições para aprender na contemporaneidade.

\section{Educação pelo rádio: lições da história}

Outras mídias estiveram presentes em nosso cotidiano e foram utilizadas na educação, como o rádio. Costa (2012) desenvolveu um importante estudo sobre esse assunto, no qual remonta algumas das primeiras experiências com o uso do rádio na educação engendradas no início do século XX. De acordo com essa autora, na década de 1930, a figura de Ariosto Espinheira se destaca como um importante nome na criação de programas radioeducativos:

Em 1936, com a inauguração da Rádio Jornal do Brasil (PRF4), Espinheira foi convidado para dirigir a programação infantil desta emissora. Dentre as atrações por ele elaboradas nessa emissora estava a Viagem através do Brasil, irradiada nas manhãs das terças, quintas e domingos. Ainda no final da década de 1930, o conteúdo deste programa foi transformado em uma coleção paradidática, editada pela Companhia Melhoramentos. Nesse período, Espinheira também assinava a coluna Livro Aberto às crianças do Jornal do Brasil, onde eram publicados cartas de ouvintes, resumos e ilustrações dos programas irradiados. (COSTA, 2012, p. 104).

Importante destacar que nessa época ainda não se tinha um sistema de educação universalizado no país e, nesse sentido, o rádio passou a funcionar como um meio pelo qual se fazia chegar programas educativos nos lugares mais distantes do país. Os programas eram produzidos considerando a sua integração com as escolas existentes no país e, por isso, tinha forte preocupação com a figura do professor para quem os programas eram destinados. Mesmo 
assim, a utilização desses programas pelo magistério da época gerava muitas angústias, pois representava uma grande novidade.

A implementação do projeto de rádio escola compreendia além de aspectos técnicos, a questão do magistério, fundamental para que o rádio de fosse efetivamente incorporado ao cotidiano escolar. $\mathrm{O}$ veículo era uma novidade para a maior parte da população. Os professores conviviam pela primeira vez com tal artefato em sala de aula e tinham muitas dúvidas quanto à sua utilização e à sua eficácia. Neste aspecto, uma das maiores angústias que acompanhava o magistério era o receio de que o rádio pudesse substituir a figura do professor. (COSTA, 2012, p. 105).

Conforme registrado por Costa, a concepção de educação via rádio, de Ariosto Espinheira, considerava, na década de 1930, uma formação ativa e crítica dos sujeitos que dela participavam.

Ariosto Espinheira destacava que a função da radioeducação não é ensinar conceitos, mas sim despertar nos ouvintes o interesse espontâneo pelo estudo. Desta forma, ele enfatizava que os programas deveriam ser mínimos, e permitir que os alunos interviessem o mais possível, para que sejam colaboradores e não meros receptores, ouvintes passivos. (COSTA, 2012, p. 105).

O analfabetismo adulto é uma das grandes preocupações que marcam a história da educação brasileira no início do século XX. As décadas de 1920-30 marcam as primeiras iniciativas no sentido de tentar superar essa questão. Contudo, a primeira iniciativa governamental para enfrentamento dessa questão foi a criação da Campanha Nacional de Adolescentes e Adultos (CEAA), em 1947. Essa é a primeira campanha de abrangência nacional, implementada pelo Ministério da Educação e Saúde. Porém, embora tivessem sido criadas 10 mil classes em todo o território nacional, a campanha não conseguiu fazer frente ao enorme desafio de modificar significativamente os índices de analfabetismo no Brasil. A campanha perdurou até o final da década de 1950, quando foram criadas outras duas campanhas subsidiadas pelo governo federal: Campanha Nacional de Educação Rural (CNER, em 1952) e a Campanha Nacional de Erradicação do Analfabetismo (CNEA, em 1958). No bojo dessas ações de enfrentamento à questão do analfabetismo, destaca-se também a criação, em 1958, do Sistema Radioeducativo Nacional (SIRENA), que desenvolvia programas de alfabetização de adultos via sistema de rádio, tendo como base um projeto-piloto realizado em Leopoldina-MG. De acordo com Baumworcel (2008, p. 6):

O SIRENA foi criado em 1958 e durou até 1963, quando foi incorporado pela Rádio Educadora de Brasília. Muitas emissoras católicas tinham convênio com o SIRENA e a partir desse sistema criavam escolas radiofônicas 
distribuindo aparelhos receptores pelos párocos. Algumas dessas escolas, num primeiro momento, foram incorporadas pelo MEB, que mudou radicalmente a forma de produção e emissão de aulas e programas radiofônicos, que passaram a ser descentralizadas das escolas, com treinamento de monitores, e a recepção organizada das aulas e apoio da supervisão.

No início dos anos 1960, outra importante iniciativa de educação via rádio foi o Movimento de Educação de Base (MEB), realizado numa parceria entre o governo federal e a Conferência Nacional dos Bispos do Brasil (CNBB) para realização de classes de alfabetização de adultos, utilizando os sistemas radioeducativos já existentes nas dioceses da Igreja Católica.

Em 1961, o MEB inicia suas atividades com onze sistemas radioeducativos ${ }^{\mathrm{vii}}$, presentes em oito estados da federação. Nesse momento dispunha também de 2.687 escolas radiofônicas e 1.182 monitores e animadores. Três anos depois, em 1964, o MEB já possuía 55 sistemas, presentes em 15 estados (que contava com 22 estados na federação), 4.554 escolas radiofônicas e um total de 3.147 monitores e animadores treinados.

Quanto ao número de alunos concluintes, o MEB passa de 38.734 em 1961 para 63.758 em 1964, quase o dobro (COSTA; JACCOUD; COSTA 1986). De acordo com Fávero (2004, p. 21): "sua meta era implantar, no primeiro ano de funcionamento, 15 mil escolas radiofônicas para a alfabetização de cerca de 500 mil pessoas". Isso por si só já representa uma diferença marcante em relação aos outros movimentos de educação e cultura popular em curso no Brasil naquele momento. O Movimento de Cultura Popular, a Campanha de Pé no Chão Também se Aprende a Ler, e as próprias experiências de Paulo Freire eram localizadas e não tinham a pretensão de uma abrangência que o MEB conseguiu ter por meio da a utilização do rádio naquele momento.

$\mathrm{O}$ rádio das experiências acima não se compara à reinvenção que essa mídia de comunicação tem na contemporaneidade, em que é difundido, inclusive, por meio da internet, de forma a ouvir, ver e participar, em tempo real, com uma grande parte das rádios do Brasil e do mundo por dispositivo móvel e computador. Porém, no passado e no presente as questões das desigualdades sociais permanecem.

Os exemplos da história nos mostram como experiências educativas realizadas com meios não presenciais não são uma novidade. Algumas dessas experiências apontam para a importância da formação crítica e autonomia dos sujeitos que dela se utilizam. 


\section{Desconstrução do paradigma da internet para/com/de todos: o que não podemos esquecer}

No primeiro momento da pandemia, as discussões estavam voltadas para reconhecer o que e como fazer, exacerbando ainda mais os temas da exclusão digital e da desigualdade. $\mathrm{O}$ assunto tem gerado debates que podem ser acompanhados no meio virtual, por exemplo nas lives $^{\text {viii }}$. Mas a relação do usuário com a tecnologia não se limita ao acesso, há o contexto que abrange o econômico, o social e o cultural dos sujeitos.

Todos os documentos relativos à educação, exibidos no cronograma (Imagem 1), mencionam de alguma forma o acesso on-line e apenas a proposta para o ensino, com algumas diretrizes do CNE, faz consideração sobre a desigualdade:

Há ainda que se observar a realidade das redes de ensino e os limites de acesso dos estabelecimentos de ensino e dos estudantes às diversas tecnologias disponíveis, sendo necessário considerar propostas inclusivas e que não reforcem ou aumentem a desigualdade de oportunidades educacionais. (BRASIL, 2020g, p. 6).

O contexto da pandemia do novo coronavírus revela, ainda, que o espaço da internet tem marcas da desigualdade. Fato que se contrapõe ao senso comum de que: todos têm acesso à internet, os jovens têm naturalmente desenvolvido conhecimentos sobre esse território, e por isso é um espaço igual para todos. Pode parecer que, devido à desenvoltura com as mídias, os jovens desenvolvem estratégias de letramento midiático, porém, pesquisas nesta área desmistificam essa impressão (LIVINGSTONE, 2011; PISCHETOLA, 2016). Os jovens não são nativos digitais, porque dominam os usos das tecnologias. O letramento nas mídias envolve sociabilidade, leitura, interpretação e compartilhamento de conteúdo. Educar o olhar e os processos de aprendizados nesse espaço é papel também da escola.

A realidade no território brasileiro tem muito mais complexidade envolvida do que o discurso recorrentemente difundido. O IPEA (2019) aponta que ocorreu aumento no acesso à internet, mas que isso não corresponde a uma significância quando se refere à classe baixa da população, com diferenças maiores entre as áreas urbanas e rurais. $\mathrm{O}$ estudo ocupou-se ainda das práticas acumulativas dos grupos sociais, e mostra que "os usuários que possuem menor capital de experiência com a internet, por sua vez, serão provavelmente também os que desenvolverão práticas mais restritas e circunstanciais. ” (p. 46).

O serviço de internet tem um custo. Para se manter conectado, pode-se usar o sistema wi-fi (localização fixa) ou dados móveis (em deslocamento). Na pandemia, os estudantes estão em suas residências e a contratação do serviço de internet estará vinculada, portanto, à sua realidade econômica. Acessar no local de trabalho, na instituição de educação, em lojas, ônibus 
e outros espaços que disponibilizam o acesso sem custo são estratégias para não ficar à margem da conectividade e minimizando custos.

A Pesquisa Nacional por Amostra de Domicílios Contínua (PNAD), com base em dados do ano de 2019 (IBGE, 2020) apresenta os índices da desigualdade no país. Os dados revelam que não houve retração no índice de desigualdade de 2018 para 2019. Na série apresentada de 2015 a 2019 o índice de 0,509 se mantém o mais alto. O Nordeste continua sendo a região mais afetada. Quanto a bens, a pesquisa indica que nos domicílios que recebiam o Bolsa Família, $12,6 \%$ tinham microcomputador; no grupo que não recebiam o benefício, 45,6\% possuíam computador.

A "Pesquisa sobre o uso das tecnologias da informação e comunicação nos domicílios brasileiros: TIC Domicílios 2019” (2019) - realizada pelo Centro Regional de Estudos para o Desenvolvimento da Sociedade da Informação (Cetic.br), com organização das Nações Unidas para Educação, a Ciência e a Cultura (UNESCO) - demostra a redução da quantidade de computadores de mesa nas residências: no total de domicílios pesquisados, $66 \%$ possuem notebook, $41 \%$ têm computador e 33\% dispõem de tablet. O celular é o equipamento mais usado: $58 \%$ declaram acessar a internet somente pelo celular. Outro destaque da pesquisa são as atividades na internet, pois $73 \%$ dos pesquisados utilizam para comunicação, $47 \%$ buscam informações sobre saúde, 33\% exercem atividades de trabalho e 39\% realizam compras pela internet. $\mathrm{Na}$ educação, os dados de 2019 revelam que do total de usuários da internet: 41\% realizaram atividades ou pesquisas escolares; $40 \%$ estudaram por conta própria; $12 \%$ fizeram curso a distância.

As pesquisas apresentadas (CETIC.BR, 2019; IBGE, 2020; IPEA, 2019) corroboram com a discussão de que o uso de celular como bem pessoal não significa acesso permanente, o que ficou notório nesse momento de pandemia. As pesquisas não trazem dados do letramento midiático, porém temos acompanhado relatos de estudantes e de professores com dificuldades em relação ao acesso e também as questões de letramento. $O$ fato é que estamos imersos nas mídias e pouco se investiu sobre as habilidades a serem desenvolvidas neste universo, tanto para os estudantes, quanto em formação inicial aos professores.

O estudo longitudinal, apresentado por Vered, Eshet-Alkalai e Geri (2019), rastreou pesquisas a fim de compreender as tendências nos estudos sobre competências no letramento digital essenciais do século XXI. Inicialmente os autores identificam sete habilidades principais a serem desenvolvidas: colaboração; comunicação; criatividade; pensamento crítico; conhecimento de informação; resolução de problemas e habilidades socioemocionais. A pesquisa mapeou o campo de produção teórica sobre essas habilidades, que se relacionam à 
educação. Predominam, na ordem das pesquisas, as habilidades de comunicação, solução de problemas e colaboração.

A pesquisa também indica que a área da educação tem investido pouco em investigações sobre as habilidades no letramento digital. Ao refletirmos sobre as habilidades elencadas pelos autores problematizamos que estas podem ser consideradas as habilidades necessárias ao desenvolvimento dos estudantes, visando sua autonomia e liderança na condução do seu processo de conhecimento; empoderados em atitudes que os levem a ser participativos, reflexivos, solidários e respeitosos em sociedade. A escola pode aprender com a situação atual e repensar suas práticas, no sentido de além dos conteúdos, desenvolver habilidades para o letramento nas mídias. Diante dos usos das mídias na produção do conhecimento e no estreitamento de territórios, compreendemos que o acesso aberto da internet para as classes populares se faz necessário nesse momento e numa sociedade plural e cidadã.

O período de distanciamento social tem nos levado a refletir sobre o campo da exclusão do direito à educação. Entre aula remota e via rádio existe uma diferença enorme para o aprendizado. Precisamos ousar, chamar os setores, os dirigentes, os conselhos de educação e desburocratizar os processos, avançando nessa discussão. Porém, antes disso, temos a difícil missão de nos mantermos vivos e lúcidos diante da crise sanitária e política em que se encontra o Brasil.

\section{Considerações finais}

A pandemia criada pela disseminação do novo coronavírus no mundo e, com ela, a necessidade de implantação de medidas de isolamento social recolocam as mídias na discussão sobre educação. Na mesma medida em que são apontadas como um canal para enfrentamento desse momento, seu uso indiscriminado cria muitas confusões em todos os níveis de ensino. Existem muitas e diferentes compreensões nos discursos de professores, estudantes, pais, gestores e pesquisadores, mas ainda precisamos de estudos e avaliações sobre o que o uso de mídias para a educação representa para esse momento específico e para o que representará no futuro pós-pandemia.

O período pós-pandemia tem gerado muitas especulações, com projeções, para o bem e para o mal. Algumas delas são cabíveis de crítica, como o uso das mídias em larga escala para todas as redes de ensino, em todos os níveis de educação. Essa ideia ronda o interesse de empresários e sistemas de ensino, mas nunca antes encontrou efetividade. A pandemia do novo coronavírus criou o cenário ideal para que aqueles que acreditam ser possível uma educação 
nesses termos, engendrem estratégias de tornar isso uma realidade. O momento pós-pandemia passará, entre outras coisas, pelas políticas que serão propostas e pela possibilidade de mobilização de todos os setores que compõem a sociedade e que discutem os caminhos da educação.

Sem a pretensão de fazer afirmativas absolutas, buscamos refletir sobre o momento presente a partir do que discutimos neste artigo. A primeira delas é que os usos de mídias em educação têm seu lugar, é uma realidade do nosso tempo e se disponibilizada de forma planejada e organizada, representa uma possibilidade de diminuição das desigualdades educacionais.

Há que se considerar a mediação pedagógica com o uso de mídias, contudo não podemos acreditar que esta substitua a educação presencial. O processo educacional não acontece apenas pelo conteúdo, pelas tecnologias, mas por meio da mediação humana com todas as suas “incompletudes" (para usar aqui um termo freireano). A dimensão humana está presente no ato de interação entre pessoas no ambiente educacional on-line. Não desconsideramos isso. Porém, estamos aqui evocando o toque, o olho no olho, as emoções do cotidiano, a afetividade e os desafetos que compõem a aventura da relação, presentes nos processos educativos.

A segunda reflexão é sobre como esse tempo de pandemia aumenta a percepção a respeito da existência de um enorme sistema de desigualdade que marca o Brasil em muitos âmbitos, inclusive na educação. Para efeito da discussão sobre educação e uso de mídias, como abordamos neste texto, encontra relação entre a desigualdade atrelada à exclusão ou limitação às mídias. As alternativas do rádio e da $\mathrm{TV}$, que alguns estados e municípios adotaram como caminhos viáveis, deixa latente a discussão sobre a democratização aos bens culturais. A internet deveria ter seu sinal aberto a todos para o livre acesso como um bem público. Compreendemos os espaços educativos, presenciais ou não, hoje vinculados ao letramento midiático, numa perspectiva de educação para maior participação social e profissional.

A falta de uma parceria entre o MEC, o Conselho Nacional de Secretários de Educação (CONSED), a União Nacional dos Dirigentes Municipais de Educação (UNDIME) entre outros, faz com que as medidas educacionais sejam organizadas de forma independente, refletindo em decisões e resultados isolados. Muito do que está sendo realizado é mediante os erros e acertos de outros países. O Brasil ainda precisa avançar mais quando se trata da democratização de bens culturais.

$\mathrm{O}$ ensino remoto, on-line, à distância, via TV, via rádio, seja qual for, não pode ser entendido ou confundido como extensão do ensino presencial. Cada um tem o seu lugar para atender as diferentes exigências do momento. A pandemia mostra o quanto podíamos ter 
avançado na democratização do acesso e do letramento. Esse momento que vivemos nos mostra a necessidade cada vez maior de investir na formação de sujeitos críticos e autônomos diante da informação, produtores de conteúdo, que abandonem a reprodutividade e sejam capazes de gerenciar sua aprendizagem. Essa, talvez, seja uma velha lição que já sabíamos, mas que provavelmente precisamos reaprender. Como diz Antônio Cicero de Souza (Ciço), um lavrador de Caldas Novas, cujo pensamento foi registrado por Brandão (1985, p. 198): “E esse quem? É o saber que tá faltando pro povo saber?"

\section{Referências}

BAUMWORCEL, A. As escolas radiofônicas do MEB. In: CONGRESSO DE HISTÓRIA DA MÍDIA. 6., 2008, Niterói. Anais eletrônicos [...]. Niterói, 2008.

BRANDÃO, Carlos Rodrigues (org.). A questão política da educação popular. 5. ed. São Paulo: Brasiliense, 1985.

BRASIL. Ministério da Educação. Lei no 9.394, de 20 de dezembro de 1996. Estabelece as diretrizes e bases da educação nacional. Diário Oficial [da] República Federativa do Brasil, Poder Executivo, Brasília, DF, 23 dez. 1996. Seção 1, p. 27833.

BRASIL. Ministério da Educação. Decreto no 9057, de 25 de maio de 2017. Regulamenta o art. 80 da Lei $\mathrm{n}^{\circ}$ 9.394, de 20 de dezembro de 1996, que estabelece as diretrizes e bases da educação nacional. Diário Oficial [da] República Federativa do Brasil, Poder Executivo, Brasília, DF, Brasília-DF, 30 maio 2017.

BRASIL. Ministério da Educação. Portaria Normativa nº 2117, de 06 de dezembro de 2019. Dispõe sobre a oferta de carga horária na modalidade de Ensino a Distância em cursos de graduação presenciais ofertados por Instituições de Educação Superior pertencentes ao Sistema Federal de Ensino. Diário Oficial [da] República Federativa do Brasil, Brasília-DF, 11 dez. 2019. Seção 1, p. 66.

BRASIL. Ministério da Saúde. Portaria no 356, de 11de março de 2020. Dispõe sobre a regulamentação e operacionalização do disposto na Lei $\mathrm{n}^{\circ} 13.979$, de 6 de fevereiro de 2020 , que estabelece as medidas para enfrentamento da emergência de saúde pública de importância internacional decorrente do coronavírus (Covid - 19). Diário Oficial [da] República Federativa do Brasil, Brasília-DF, 12 mar. 2020a. Seção 1, p. 185.

BRASIL. Ministério da Educação. Portaria Normativa n 343, de 17 de março de 2020. Dispõe sobre a substituição das aulas presenciais por aulas em meios digitais enquanto durar a situação de pandemia do Novo Coronavírus - Covid-19. Diário Oficial [da] República Federativa do Brasil, Brasília-DF, 18 mar. 2020b. Seção 1, p. 39.

BRASIL. Ministério da Educação. Portaria Normativa n 345, de 19 de março de 2020. Altera a Portaria MEC no 343, de 17 de março de 2020. Diário Oficial [da] República Federativa do Brasil, Brasília-DF, 19 mar. 2020c. Seção 1, p. 1. 
BRASIL. Ministério da Educação. Portaria Normativa $n^{0}$ 356, de 20 de março de 2020. Dispõe sobre a atuação dos alunos dos cursos da área de saúde no combate à pandemia do Covid-19 (coronavírus). Brasília, DF, 2020d.

BRASIL. Presidência da República. Medida Provisória $n^{\circ}$ 934, de $1^{\circ}$ de abril de 2020. Estabelece normas excepcionais sobre o ano letivo da educação básica e do ensino superior decorrentes das medidas para enfrentamento da situação de emergência de saúde pública de que trata a Lei n ${ }^{\circ} 13.979$, de 6 de fevereiro de 2020. Diário Oficial [da] República Federativa do Brasil, Brasília-DF, $1^{\circ}$ abr. 2020e. Seção 1, p. 1.

BRASIL. Ministério da Educação. Portaria Normativa no 376, de 3 de abril de 2020. Dispõe sobre as aulas nos cursos de educação profissional técnica de nível médio, enquanto durar a situação de pandemia do novo coronavírus - Covid-19. Diário Oficial [da] República Federativa do Brasil, Brasília-DF, 6 abr. 2020f. Seção 1, p. 66.

BRASIL. Conselho Nacional de Educação-CNE. Parecer $n^{\circ}$ 5, de 24 de abril de 2020. Reorganização do Calendário Escolar e da possibilidade de cômputo de atividades não presenciais para fins de cumprimento da carga horária mínima anual, em razão da Pandemia da Covid-19. Diário Oficial [da] República Federativa do Brasil, Brasília, DF, $1^{\circ}$ jun. 2020g, Seção 1, p. 32.

CENTRO REGIONAL DE ESTUDOS PARA O DESENVOLVIMENTO DA SOCIEDADE DA INFORMAÇÃO (CETIC.BR). Pesquisa sobre o uso das tecnologias da informação e comunicação nos domicílios brasileiros: TIC Domicílios 2019. Disponível em: https://www.cetic.br/pesquisa/domicilios/. Acesso em: 14 maio 2020.

COSTA, M. A. B.; JACCOUD, V.; COSTA, B. (org.). MEB: uma história de muitos. Cadernos de Educação Popular, n. 10. Petrópolis: Vozes, 1986.

COSTA, P. C. da. Educadores do rádio: concepção, realização e recepção de programas educacionais radiofônicos (1935-1950). Tese (Doutorado Educação) - Universidade de São Paulo, São Paulo, 2012.

FÁVERO, O. Lições da história: os avanços de sessenta anos e a relação com as políticas de negação de direitos que alimentam as condições do analfabetismo no Brasil. In: PAIVA, J.; OLIVEIRA, I. B. de. (org.). Educação de Jovens e Adultos. Rio de Janeiro: DP\&A, 2004. p. 09-21.

HOLSHUE, M. L. et al. First case of 2019 novel coronavirus in the United States. N Engl J Med, v. 382, n. 10, p. 929-936, 2020.

INSTITUTO BRASILEIRO DE GEOGRAFIA E ESTATÍSTICA (IBGE). Rendimento de todas as fontes 2019: Pesquisa Nacional por Amostra de Domicílio Contínua (PNAD). Rio de Janeiro, 2020.

INSTITUTO DE PESQUISA ECONÔMICA APLICADA (IPEA). As tecnologias digitais e seus usos. Texto para discussão. Brasília: Rio de Janeiro, 2019.

LESCURE, F. X. et al. Clinical and virological data of the first cases of Covid-19 in Europe: a case series. Lancet Infect Dis, v. 20, n. 6, p. 697-706, 2020. 
JIMENEZ, Marco Raúl Mejía. Uma nova humanização desde o Sul, para construir novas educações. In: COSTA, R. P.; VIANNA, V. M. Entrelaçando olhares por uma educação planetária. Rio de Janeiro: Caetés, 2014. (Seminários NEAd 3). p. 49-76.

LIVINGSTONE, Sonia. Internet literacy: a negociação dos jovens com as novas oportunidades on-line. Matrizes, ano 4, n. 2, p. 11-42, 2011.

PIMENTEL, M.; CARVALHO, F. da S. P. de. Princípios da educação on-line para sua aula não ficar massiva nem maçante. SBC Horizontes [on-line], 23 maio 2020.

PISCHETOLA, Magda. Inclusão digital e educação: a nova cultura da sala de aula.

Petrópolis: Vozes, 2016.

SILVA, M. Educação a distância (EaD) e educação online (EOL) nas reuniões do GT 16 da ANPEd (2000-2010). Revista Teias, v. 13, n. 30, p. 95-118, 2012.

SILBER-VAROD, V.; ESHET-ALKALAI, Y.; GERI, N. Tracing research trends of 21 stcentury learning skills. British Journal of Educational Technology, v. 0, n. 0, p. 1-20, 2019.

WANDERLEY, L. E. W. Educar para transformar: educação popular, Igreja Católica e política no Movimento de Educação de Base. Petrópolis: Vozes, 1984.

WEISER, O.; BLAU, I.; ESHET-ALKALAI, Y. How do medium naturalness, teachinglearning interactions and Students' personality traits affect participation in synchronous Elearning? The Internet and Higher Education, v. 37, p. 40-51, 2018.

WORLD HEALTH ORGANIZATINON (WHO). Coronavirus disease (Covid-19) pandemic. Geneva, 2019. Disponível em: https://www.who.int/emergencies/diseases/novel-coronavirus2019. Acesso em: 30 maio 2020.

\footnotetext{
i Doutoranda em Educação pelo Programa de Pós-Graduação em Educação da Pontifícia Universidade Católica do Rio de Janeiro (PUC-Rio). Bolsista da Coordenação de Aperfeiçoamento de Pessoal de Nível Superior (CAPES). Professora no município de Angra dos Reis. E-mail: kelly05maia@gmail.com. Angra dos Reis-RJ, Brasil. ORCID: https://orcid.org/0000-0002-4711-8271. O presente trabalho foi realizado com apoio da CAPES - Código de Financiamento 001.
}

\footnotetext{
ii Doutor em Educação pelo Programa de Pós-Graduação em Educação da Pontifícia Universidade Católica do Rio de Janeiro (PUC-Rio). Professor do Departamento de Educação da PUC-Rio e professor substituto na Universidade Federal Rural do Rio de Janeiro (UFRRJ) E-mail: recostta@puc-rio.br. Rio de Janeiro, Brasil. ORCID https://orcid.org/0000-0002-7654-7593.
}

\footnotetext{
iii De acordo com Mejía (2014, p. 66): "Esse viver bem e bem viver se difere da 'boa vida' do pensamento keynesiano, que toma como base nossas culturas ancestrais localizadas em três tradições: o mundo quechua, a ideia SUMAK KAWSAY (a vida em plenitude e harmonia) no mundo kuna BALUWABA (a unidade da natureza) e no aymara SUMA OAMAÑA (o bem-estar de sua força interior), todas referidas a um mundo no qual, na esfera da linguagem, cria-se uma categoria que torna visível seu projeto de vida, fundado na unidade do mundo, sem separações nem dicotomias."

iv Para mais informações referentes aos primeiros casos nos Estados Unidos da América (EUA) e na França ver Holshue et al (2020) e Lescure et al (2020), respectivamente, e World Health Organization (WHO, 2020).
} 
${ }^{\vee}$ Em 17 de abril de 2020, o CNE realizou chamada pública com objetivo de receber propostas sobre o texto de referência ao parecer, em 28/04/2020 foi divulgada a versão final do texto e em 01/06/2020 ocorreu a publicação do parecer em Diário Oficial.

vi Trata-se de uma pesquisa em espaço e cultura diferente do Brasil, mas que pode suscitar reflexões ao contexto brasileiro, pois algumas instituições adotaram o ambiente ZOOM e aulas síncronas no período da pandemia.

vii De acordo com Wanderley (1984, p. 53): "O Sistema Radioeducativo tinha características gerais similares em todo o país, em que pese o fato de que cada sistema e cada equipe local possuírem sua originalidade e características específicas. Cito alguns excertos de publicações do MEB, para uma visão de conjunto, e informações amplas sobre algumas práticas efetuadas. 'O Sistema Radioeducativo é constituído por uma rede de núcleos com recepção organizada de programas educativos especialmente elaborados, com supervisão periódica, com trabalho de comunidade e escola. Para o funcionamento desses Sistemas são necessários: - um estudo prévio da área em que se vai atuar, - a escolha e o treinamento de pessoal das próprias comunidades para a direção das atividades, - a realização de uma supervisão periódica que acompanhe o desenvolvimento das escolas e comunidades e a eficácia da programação [...]. (MEB Nacional, Relatório de 1963)'.”

viii Interface audiovisual, em tempo real que permite a presença de um público. Pode chegar a um milhão de pessoas sincronizadas ao mesmo tempo de qualquer parte do planeta. Essas plataformas geralmente estão vinculadas ou são compartilhadas em redes sociais, como YouTube, Instagram, Facebook, etc. 